\title{
THRIFT.
}

\section{AN ADDRESS TO THE WORKING CLASSES.}

\author{
By Henry Law, M.Inst.C.E.
}

Fellow working men, for I claim to be a working man in as real and full a sense as any one of you who are here present to-night, and $I$ know of no title more honourable or more to be desired than that of a working man.

A recent writer, speaking of working men, has remarked"They belong to the ancient and honourable family of workers -that extensive family which constitutes the backbone of our country's greatness-the common working people of England."

The real measure of the worth of a man is not the social rank which he may hold-does not depend upon the number of grenerations through which he can trace his descent, or how many of his ancestors have been known to fame, or as the possessors of wealth; but it is - What has that man done in his own person and life to promote the welfare or the material progress of himself and his fellow men?

Assuming this as our gauge, we may confidently affirm that all men who have attained greatness have been working men; that is to say, men who have worked earnestly and continuously, either with their hands or their head, or with both, in that particular calling or occupation which the accident of birth or other circumstances may have assigned to them. And we may further assert that in a very great majority of cases the greatest men, and those who have proved the greatest benefactors to their fellow men, those to whom we owe some of the most important and useful inventions, have risen from the humblest ranks of working men.

The time allotted me this evening would not suffice to allow of my giving you the names of even a tithe of those men, who, born in the most humble ranks of life, have attained to greatness and 
become the benefactors of their fellow men; amongst those, however, whose names will be most familiar to you I may mention the following, namely: George Stephenson, who rose from being a cowboy earning twopence a day, and became the father of the locomotive and of the existing system of railways; 'Thomas Telford, who rose from being a shepherd, to become one of the most noted engineers, the constructor of the Menai suspension bridge, and many other important works, and was the founder and first President of the Institution of Civil Engineers ; James Brindley, who from an ordinary labourer, became the engineer of the Bridgewater canal and many other important engineering works; Sir Richard Arkwright, a name specially to be hououred in Bolton, who rose from being a barber, to make the most important improvements in the machinery for the manufacture of cotton goods; Samuel Crompton, another Bolton man, whose father was a small farmer, and who was the inventor of the spinning-mule; Robert Hawthorne, the father of the well-known Newcastle engineer, who was originally engineer at the same colliery at Dewley, at which George Stephenson was fireman; Michael Faraday, the chemist, who was a bookbinder's apprentice; Sir Isaac Newton, who was the

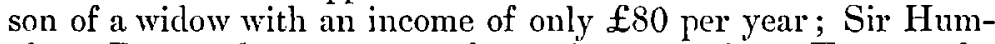
phrey Davy, who was an apothecary's apprentice; Turner, the well-known painter, who was originally a barber; George Bidder, the well-known engineer, who possessed sucl extraordinary powers of calculation, and was the son of a stonemason; Jesse Hartley, for many years the engineer of the Liverpool docks, who was a working mason; Shakespeare, Burns, Ben Jonson, Cook the navigator, Hugh Miller the geologist, the first Sir Robert Peel, Jacquard, the inventor of the loom which bears his name; Bunyan, the author of the Pilgrim's Progress, Newcomen, the improver of the steam engine, Chantrey the sculptor, Sir Thomas Lawrence the painter, Richard Cobden, Flaxman the Sculptor, Dr. Livingstone the African traveller, Gainsborough the painter, John Dalton, Sir William Herschel the astronomer, and many other eminent men, who want of time forbids me to mention, all rose from the most humble ranks of life.

It may be confidently said that nearly all the most important and useful discoveries and inventions have been made by those who have risen from the more humble ranks of working men. Smiles, in his life of George Stephenson, remarks, - "It is certainly a striking and remarkable fact that nearly all that has been done for the improvement of the steam engine has been accomplished, not by philosophers and scientific men, but by labourers, mechanics, and enginemen. The steam engine was but a mere toy until it was taken in hand by workmen. 
Savery was originally a working miner, Newcomen a blacksmith, and his partner Cawley a glazier. In the hands of Watt, the instrument maker, who devoted almost a life to the subject, the condensing engine acquired gigantic strength; and George Stephenson, the colliery engineman, was certainly not the least of those who have assisted to bring the high-pressure engine to its present power."

It may, I think, without fear of contradiction be said, that we owe our greatness as a nation chiefly, if not entirely, to the labours of our working men.

Such being the case, it becomes an interesting and profitable subject for enquiry to ascertain what are those peculiar qualities in our working men which have led, in so many instances, to the attainment of such strikingly successful results, and I hope to be able to convince you that those qualities may be shown to be summed-up and expressed by the one word, THRIFT.

Now, "thrift" is derived from the verb to "thrive," and to thrive from the Icelandic word throa, to increase, and, according to Johnson, "thrift" means "profit, gain, riches gotten, state of prospering," while the verb to " thrive" means to "increase, prosper, grow rich, advance in anything desired."

I clare say, on first hearing the word thrift, your thoughts turned to the subject of money, and you associated with the word the saving of money; but I desire this evening to clirect your attention, not so much to thrift as regards money, but rather as applied to thrift of time and health, both of which, however, mean gain of money and material wealth.

Now, while thrift of money means frugality, economy, and care in making investments, thrift of time means industry, perseverance, and punctuality, and thrift of health means that talking care of our bodies which leads to the maintenance of health, energy, and unimpaired powers, both of mind and body.

These are the qualities which lead to success in life, and enable working men to attain to the position of eminence and usefulness of which I have cited a few examples. This fact was expressed by $\mathrm{Mr}$. Bright in addressing an assembly of working men at Rochdale just forty years ago, when he said: "There is ouly one way that is safe for any man, or any number of men, by which they can maintain their present position if it be a good one, or raise themselves above it if it be a bad one, that is, by the practice of the virtues of industry, frugality, temperance, and honesty. There is no royal road by which men can raise themselves from a position which they feel to be uncomfortable and unsatisfactory as regards their mental or physical condition, except by the practice of those virtues by 
which they find numbers amongst them are continually advancing and bettering themselves."

The more you study the careers of such of these eminent men who have risen from the ranks of labouring men as have had their lives published, the more convinced you will become of the truth of the foregoing statements. If, for example, we take the career of George Stephenson, we find it marked by the utmost frugality, industry, and the devotion of all his leisure time to the acquirements of a knowledge of reading, writing, and mechanics, and we find him constantly engaged in athletic sports, presenting a remarkable instance of thrift of money, time, and health.

The early career of the firm of Yates, Peel, \& Co., of which the first Sir Robert Peel and his father-in-law were the founders, exhibits the same striking instance of thrift. Smiles, in his "Self-Help," narrates as follows:- "The frugal style in which the partners lived may be inferred from the following incident in their early career. William Yates being a married man with a family, commenced housekeeping on a small scale, and to oblige Peel, who was single, he agreed to take him as a lodger. The sum which the latter first paid for board and lodging was only eight shillings a week, but Yates, considering this too little, insisted on the weekly payment being increased a shilling, to which Peel at first demurred, and a difference between the partners took place, which was eventually compromised by the lodger paying an advance of sixpence a week."

Passing, however, from the subject of the thrift of money to that of time, it is impossible to overrate the importance of the latter. I have already remarked that thrift of time involves industry, perseverance, and punctuality. Industry, not only during the hours given to the daily work, the necessity and importance of which is the character and reputation which it secures to the working man of an honest desire to faithfully perform his duty; but what I more especially refer to as the thrift of time is the habit of devoting those leisure moments, which must occur in the busiest man's daily life, to some useful purpose. Young has termed the leisure moments which occur in daily life the "gold-dust of time," and such they truly are. There is a well known anecdote of the great naturalist Buffon, which illustrates this subject. Constitutionally he was of an indolent disposition, but he formed the resolution to rise early in order to prosecute his great work on natural history. Finding, however, that the attraction of his bed was stronger than his resolution, he directed his servant Joseph to compel him to rise, promising him half-a-crown for every time that he made him leave his bed before six o'clock, and this Joseph faithfully 
did, notwithstanding the remonstrances and threats of his master of immediate dismissal, followed an hour or two after by the promised reward; and Buffon was accustomed to say that he owed to his servant Joseph three or four of the volumes of his work on natural history.

The importance of thrift of time will be appreciated when it is considered that lost time can never be recovered, it is irrevocably gone for ever, and no subsequent regret can ever recall it; lost money may be recovered, even lost health may sometimes be restored, but lost time is a loss which no effort or exertion can ever replace. Such being the case, it behoves every man whose desire is to succeed in life to be specially careful to save the "gold-clust of time" which may fall to his share.

In 'Smiles' "Life of George Stephenson," he remarlis : "Perhaps the secret of every man's best success in life is the readiness with which he takes advantage of opportunities. George Stephenson was an eminent illustration of this readiness in turning all his time to profit, and everything that he knew to useful account. Every spare minute was laid under contribution, either for the purpose of adding to his earnings or to his knowledge. The smallest fragments of his time were regarded by him as precious; and he was never so happy as when improving them. He missed no opportunity of extencling his observations, more especially in his own immediate department; he was always acquiring new facts, and aiming at improvements in his own calling. Sometimes he failed, but his very failures only served to strengthen his hardy nature, and they eventually conducted him to success."

Another most important practice of the thrift of time is the habit of observation and attention to passing circumstances and events. Hugh Miller, the well-known geologist, has truly observed: "That the training of the mechanic,-by the exercise which it gives to his observant faculties, from his daily dealing with things actual and practical, and the close experience of life which he acquires,-better fits him for picking his way along the journey of life, and is more favourable to his growth as a man, emphatically speaking, than the training afforded by any other conclition."

Perseverance is clearly involved in the thrift of time, $f \circ r$ nothing can be a more useless or extravagant waste of time than to engage in pursuits, and to abandon them, when only partly accomplished.

Punctuality is not only essential to the thrift of our own time, but is a duty we owe to our fellow men, as a want of punctuality occasions a loss of other people's time besides our own.

I pass on now to speak of the thrift of health, a subject the 
importance of which it is impossible to overrate. For, not only will strict attention to sanitary principles prolong your lives, but it will render those lives better worth living for.

A very large proportion of you have to do with machinery, and to such it is not necessary to point out, how essential to the well working of every machine it is, that it should be kept constantly in good order, free from grit and dirt, properly oiled, and not put to heavier or rougher work than that for which it was designed: and in the case of a steam engine, the fires must be fed with a sufficient supply of proper fuel and fresh air, while the boiler must have a due supply of clean and pure water.

But the human body is a far more delicate machine than the most delicate piece of machinery ever constructed;-much more delicate even than the smallest and finest watch, and in order that the human body shall be capable of working to the greatest advantage,- - to perform the greatest amount of work, of the best description, with the least wear and tear, the same care and attention must be bestowed upon it as is necessary in the case of every other machine; whilst to maintain the living power or energy, the human body must be supplied with a due amount of fresh and pure air, and be fed with a sufficient supply of wholesome and proper food.

As in the case of the steam engine: unless the fire is fed with sufficient fuel of good quality the engine will not work satisfactorily; so with the human body: strength and the power of vigorous action cannot be maintained without a due supply of food of good and wholesome quality.

As in the case of the engine: if the boiler becomes covered with deposit, and the moving parts clogged with grease and dirt, much power will be lost; so is it also with the human body : if through neglect and want of care and cleanliness the lungs and stomach become clogged from breathing bad air and consuming unwholesome food, or if the functions of the skin, so essential to perfect health, are checked through want of frequent washing and suitable clothing.

Again, as the engine will lose power unless the boiler, cylinder, and steam-pipes be kept warm by-being lagged, or covered with some non-conducting material, and unless the condenser be kept cool, so will your health suffer unless the body be maintained at the proper temperature.

And, inasmuch as the mechanism of the human body is so much more delicate and intricate than the finest piece of machinery ever constructed, so is it more susceptible to injury and more affected by want of care and proper and constant attention. 
The time allotted me is utterly inadequate to allow of my describing to you the mechanism of the human body, even were I competent to do so, which I am not, and I must therefore content myself with such a general sketch as will enable you to understand how essential to the health and well-being of men it is to attend to those sanitary precautions which constitute the thrift of health.

We may describe the human bocly as consisting of a framework of bone, termed the skeleton, jointed in various parts to allow of freedom of motion, and protected from injury by a covering of flesh, which constitutes the main substance of the body; throughout this substance are distributed cords, or muscles, which are so attached to the several bones as to produce movements in the several parts of the body by their contraction; in the head there is a central electric telegraph station, termed the brain, which transmits through a system of conductors, termed nerves, the desires of the individual to every part of the body, controlling and directing the action of the muscles, and the movements of the body.

Now the machines with which you are familiar are constructed at first of their full dimensions, being incapable of growth, only requiring at stated intervals, the renewal of such parts as have been worn or deteriorated by constant use. In the human machine, however, up to a certain age the whole structure increases in size or grows, requiring a constant addition of fresh materials to build up the various parts of the body to the increased dimensions. But, further, the materials composing the human body are not of a permanent character, but are always being gradually removed and replaced by fresh material, so that the whole substance of the human body, even to the bones, becomes changed once in about every seven years.

Now the machinery by which this change of material and growth of the body is produced, consists of an arrangement by means of which the food is subjected to a combined mechanical and chemical process termed digestion, by which the materials suitable for the renewal and building up of the several parts of the body are separated, and reduced to a liquid form, constituting the blood.

Then within the body is a very beautiful four-barrel pump, termed the heart, fitted with proper valves, and producing a pumping action by the alternate contraction and dilation of the burrels. By the action of two of the pump barrels the blood is distributed through a system of pipes, termed arteries, which traverse every part of the body, leaving on its way the material required for the renewal and growth of the body, and taking up the effete or worn out material which the former is meant to 
replace. Another system of pipes, termed veins, receives and collects the blood which has thus been rendered impure, and return it through two main veins to the heart. The pure blood as it leaves the heart is bright red, while the impure blood returned to it is dark purple, and it is necessary, before it is again circulated through the body, that it should be restored to its original state of purity.

In order to effect this, the impure blood is conveyed to the second two pump barrels of the heart, and by them is pumped through two bags, termed lungs, in which it is brought into contact with air in a very finely divided state, and undergoes a process of slow combustion, by which the whole body is maintained at the temperature of about 98 degrees, which is marked upon our thermometers as blood-heat; and by this combustion the impurities are burnt up, forming carbonic acid gas, watery vapour, and ammonia, the purified blood being changed from a dark purple to bright red, and passing away to the heart to be again distributed throughout the body. But in order that this process of combustion may be efficiently carried on, it is necessary that the surface of the lungs should not become clogged with foreign matter.

Now, on an arerage, the heart makes 70 strokes per minute, discharging at each stroke about $1 \frac{1}{2}$ ozs. of blood against a

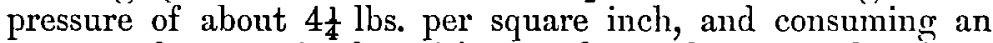
amount of energy in the 24 hours of 600 foot-tons, that is to say, 600 tons lifted to a height of one foot.

As mechanics, many of you know that a pump which has to force water through a considerable length of pipe, will not act satisfactorily without an air-vessel to equalise the flow, and in the human pumping machinery even this is provided for by the pipes being elastic, so that the pulsating motion of the heart is converted into a nearly uniform flow through the arteries and veins.

The air in the lungs having been deprived of a portion of its oxygen, and mixed with the products of combustion, namely, the carbonic acid and water, requires to be changed, and this is effected by the action termed breathing, which consists in the alternate expansion and contraction of the lungs produced by the action of the muscles on the chest. The quantity of air which is thus pumped into and out of the lungs of a grown-up person in 24 hours, varies from 400 cubic feet when no exertion is being made, to 900 cubic feet in the case of a hard-working labourer; and it has been calculated that the work which has to be performed by the muscles in the act of breathing amounts to 21 foot-tons in the 24 hours-that is equivalent to the lifting of a weight of 21 tons to a height of one foot. 
Having thus described to you the nature of the machine which constitutes the human body, you will be the better able to understand the conditions which are necessary to maintain this machine in the best possible working order.

You will immediately perceive, that if no less than from 400 to 900 cubic feet of air are passed through the lungs daily, unless the air is pure and free from dust or other foreign matter, the lungs must become clogged and their efficient action be prevented; and thus you will understand the vast importance that the air which you breathe should be pure, and provided in sufficient quantity to avoid the same air being breathed over a second time.

Again, you will understand, that the blood must be supplied with sufficient food, containing in the proper proportions the various materials required to provide for the waste constantly taking place in the several parts of the human body.

Thus for each day, the bones will require for their renewal from "half to one ounce of mineral matter, such as common salt, and phosphates of lime and magnesia ; for the nourishing of the body generally we require from $2 \frac{1}{2}$ to $4 \frac{2}{3}$ ounces of nitrogenous or albuminous food, such as eggs, meat, cheese, milk, bread, peas, lentils, \&c.; and for the production of muscular energy from 13 to $17 \frac{1}{3}$ ounces of fat and carbonaceous food, such as butter, lard, suet, sugar, and the starch of wheat, potatoes, rice, peas, \&c.; making a total of solid food, free from water, varying from 18 to 23 ounces, depending upon the greater or less muscular labour which the man has to perform.

Thus you will see, that in order to maintain the most perfect health, both the nature and quantity of the food should be varied, according to the occupation of each individual person, being increased in quantity, and especially in that of the carbonaceous food, as the person has to exert a greater or less amount of muscular energy-in other words, to perform more manual labour.

It may be taken that the total amount of energy absorbed by a living man, when in a comparative state of rest, is about 2500 foot-tons in the 24 hours, equivalent to a weight of 2500 tons being lifted to a height of one foot; and when engaged in performing an average amount of manual labour the energy exerted amounts to about 3900 foot-tons, equivalent to lifting 3900 tons to a height of one foot.

Now, I have never known a mechanic worthy of the name who did not take a pride in the engine or other machine entrusted to his care, bestowing all the attention possible to keeping it clean, bright, and in the best working order. Each one who $I$ address to-night has been entrusted with a machine 
far more perfect and beautiful in its design-far more delicate and intricate in its mechanism-than any machine constructed by human hands; and will you not take the same pride and exercise the same care, in keeping and maintaining the machine thus entrusted to you in the highest possible state of preservation, and rendcring it capable of performing the largest possible amount of work of the best possible description? I feel confident that, as true working men, such is your desire, and since thrift leads to the attainment of that which we desire, let me commend to you the practice of thrift in every form-thrift of money, thrift of time, and thrift of health. Let it be your ambition, although only working men, to equal in real worth the highest in rank of your fellows; let your constant desire be the possession of a wise head, a pure heart, and a sound body. 